\section{Lead Poisoning Due to Adulterated Marijuana in Leipzig Indication for chelator therapy should be defined critically}

by Dr. med. Franziska P. Busse, Dr. med. Georg Martin Fiedler,

Dr. med. Alexander Leichtle, Dr. med. Helmut Hentschel,

Prof. Dr. med. Michael Stumvoll in volume 44/2008

\section{Indication for Chelator Therapy Should Be Defined Critically}

In contrast to the authors' assumptions, lead intoxications have not become a rarity. According to Germany's statutory accident insurance, in 10 years more than 100 cases of lead intoxication have been recognized as an occupational disease. The real number can be assumed to be much higher. The remark that lead intoxication can be diagnosed on the basis of a lead seam is erroneous in this form. The seam is often not present and is thus not a reliable symptom. Further, the differential diagnosis to tartar (odontolithiasis) deposits is sometimes difficult. A detailed and environmental medical history mostly provides diagnostic pointers, which should be followed by measuring lead concentration in the blood.

Nausea and vomiting should be included among the gastrointestinal symptoms of lead poisoning. Symptomatic treatment for abdominal cramps can be delivered by local application of heat.

In the section entitled "Diagnosis", the authors say that the whole blood concentration indicates only acute exposure from the preceding 35 days. They are obviously confusing this with the initial (rapid) half life. In actual fact, blood lead concentrations can be increased for much longer than 35 days (1).

We don't follow the suggested chelator therapy in men with a blood lead concentration $>250 \mu \mathrm{g} / \mathrm{L}$, and in women even at $>150 \mu \mathrm{g} / \mathrm{L}$. In adults, intoxications requiring treatment do not occur in such blood concentrations. The clinical symptoms have to be taken into consideration when the indication is defined. Side effects of non-indicated chelator therapy may result in court proceedings on a charge of bodily harm.

DOl: 10.3238/arztebl.2009.0479a

\section{REFERENCES}

1. Skervfing S, Bergdahl IA. Lead: In: Nordberg GF, Fowler BA, Nordberg M, Friberg LT (Eds.): Handbook on the toxicology of metals. Amsterdam: Elsevier 2007; 599-643.

2. Busse FP, Fiedler GM, Leichtle A, Hentschel H, Stumvoll M: Lead poisoning due to adulterated Marijuana in Leipzig. Dtsch Arztebl Int 2008; 105: 757-62.

Prof. Dr. med. Axel Muttray

Institut für Arbeits-, Sozial- und Umweltmedizin

Universitätsmedizin der Johannes Gutenberg-Universität Mainz

Obere Zahlbacherstr. 67, 55131 Mainz, Germany

amuttray@uni-mainz.de

\section{Incorrectly Cited}

I read the article on lead intoxication due to adulterated marijuana with great interest (1). The authors have done a great service in alerting a wide readership to a thus far little known danger. However, the therapeutic scheme in the figure-which provides for chelator therapy in men with a blood lead concentration $>250 \mu \mathrm{g} / \mathrm{L}$ and in women above $150 \mu \mathrm{g} / \mathrm{L}$ - does not make sense at all. The guideline of the German Association for Occupational Medicine and Environmental Medicine (2) was incorrectly cited. The guideline cites human biomonitoring values I and II as stipulated by the German Federal Environment Agency (3), which does not make a recommendation for chelator therapy if the value measured is only marginally in excess of HBM value II. From the agency's publication it is clear that a higher value than HBM value II is not automatically an indication for chelator treatment (chapter 12.4, on chelators). The text of the publication does, however, slightly revise the indication for chelator therapy, by saying that such therapy is indicated if lead concentrations are above 400 $\mu \mathrm{g} / \mathrm{L}$, but even this statement is not acceptable as it stands. The clinical picture, together with the blood lead concentration, is the deciding factor. In the individual case, chelator therapy can have serious side effects. The indication therefore has to be defined critically, while balancing the risks and benefits, in order to prevent harm to the patient. In my opinion, chelator therapy should be given only with a very strict indication. The clinical picture should prompt the therapeutic decision.

DOl: 10.3238/arztebl.2009.0479b

\section{REFERENCES}

1. Busse FP, Fiedler GM, Leichtle A, Hentschel H, Stumvoll M: Lead poisoning due to adulterated Marijuana in Leipzig. Dtsch Arztebl Int 2008; 105: 757-62.

\section{2. http://www.dgaum.de}

3. Kommission „Human-Biomonitoring“ des Umweltbundesamtes. Stoffmonographie Blei Referenz- und Human-Biomonitoring-Werte (HBM). Bundesgesundheitsbl 1996; 39 :236-41.

http://www.umweltdaten.de/gesundheit/monitor/pbmono.pdf

Univ.-Prof. Dr. med. Dipl.-Ing. Stephan Letzel

Institut für Arbeits-, Sozial- und Umweltmedizin

Johannes Gutenberg-Universität Mainz

Obere Zahlbacherstr. 67

55131 Mainz, Germany

\section{Indicative of Intoxication}

The article highlights the fact that classic lead intoxication may be seen even in the 21 st century. However, the article also highlights the difficulties that many clinicians experience when interpreting biomonitoring results. The clinical finding, the medical history, and the laboratory measurements are indicative of the diagnosis. Exceeding threshold values by itself does not mean intoxication. 
The biological tolerance value (BAT) for blood lead concentrations was evaluated in 1981 at $700 \mu \mathrm{g} / \mathrm{L}$ for whole blood. Because of long term effects, the BAT value was lowered to $400 \mu \mathrm{g} / \mathrm{L}$ whole blood by the Senate Commission for the Investigation of Health Hazards of Chemical Compounds in the Work Area. In 2006 , lead was included in the cancer category 2 (animal experiment). To prevent non-carcinogenic effects, a biological reference value was formulated at the level of the former BAT value. For women of childbearing age, no reference value could be defined because of the teratogenic effects of lead. The values for women are therefore oriented along the environmental pollution values for the general population. The reference value in 1981 was $300 \mu \mathrm{g} / \mathrm{L}$ in whole blood. As the environmental pollution for the general population decreased the value for women younger than 45 years was adapted to $100 \mu \mathrm{g} / \mathrm{L}$ whole blood in 2003.

To talk about lead intoxication by definition in a scenario of the HBM II value being exceeded by 250 $\mu \mathrm{g} / \mathrm{L}$ cannot be regarded as an adequate interpretation of a measuring result. Even in the 21 st century, blood lead concentrations of $>700 \mu \mathrm{g} / \mathrm{L}$ are measured in German work places, without those exposed showing any symptoms of manifest lead intoxication.

DOl: 10.3238/arztebl.2009.0479c

\section{REFERENCES}

1. Busse FP, Fiedler GM, Leichtle A, Hentschel H, Stumvoll M: Lead poisoning due to adulterated Marijuana in Leipzig. Dtsch Arztebl Int 2008; 105: 757-62.

Prof. Dr. med. Hans Drexler

Schillerstr. 25

91054 Erlangen, Germany

\section{In Reply:}

It is certainly true that values in excess of HBM-II-value do not automatically result in symptoms of lead poisoning, but "there is an increased risk for adverse health effects and, consequently, an acute need for exposure reduction measures and the provision of biomedical care (advice). The HBM-II-value should thus be regarded as an intervention or action level" (1). The situation we described, where, owing to consumption of adulterated marijuana, mainly young adults were exposed to chronic substantial lead intake by inhalation, cannot be compared with occupational exposures. In our opinion, lead poisoning is present in patients with a whole blood lead level $>700 \mu \mathrm{g} / \mathrm{L}$ (2). In children, such a concentration is regarded as a medical emergency, which requires inpatient treatment (3). Correspondents are right to point out that the indication for chelator treatment has to be defined carefully because of the possible adverse effects. In view of the particular patient clientele (drug users with poor compliance) we had to assume that without intervention and in a scenario of continued drug use, the subsequent number of cases of severe lead poisoning would be much higher. For this reason, the decision was made to also treat users whose value was "only" in excess of the HBM-II-value. Under these circumstances, the fact that the use of chelators for chronic metal poisoning is controversial in the light of current data, was not enough to make therapeutic inactivity an option. Further, the guideline of the Association of the Scientific Medical Societies in Germany does not contain any statements of the criteria for chelator therapy (4), whereas the substance monograph on lead from the Human Biomonitoring Commission of the German Federal Environment Agency does not deem chelator therapy as indicated when whole blood levels are $<400 \mu \mathrm{g} / \mathrm{L}$ (3). To treat our patients we recommended the chelator succimer, which is well tolerated, as 2,3-dimercaptopropane-1-sulfonate (DMPS) was not available from the manufacturer for a lengthy period of time, and D-penicillamine was assessed as too dangerous for long term treatment owing to its side effect profile (risk of agranulocytosis and nephrotic syndrome).

DOl: $10.3238 /$ arztebl.2009.0480

\section{REFERENCES}

1. Umweltbundesamt: Gesundheit und Umwelthygiene. HBM- und Referenzwerte (Definitionen und Tabellen). http://www.umweltbundesamt.de/gesundheit/monitor/definitionen.htm

2. Gloxhuber C: Toxikologie. 5. Aufl. Stuttgart, New York: Georg Thieme Verlag 1994;147

3. Kommission „Human-Biomonitoring“ des Umweltbundesamtes: Stoffmonographie Blei; Referenz- und Human-Biomonitoring-Werte (HBM). http://www.umweltdaten.de/gesundheit/monitor/pbmono.pdf

4. Leitlinien der Deutschen Gesellschaft für Arbeitsmedizin und Umweltmedizin e.V. (DGAUM): Arbeit unter Einwirkung von Blei und seinen Verbindungen. http://www.uni-duesseldorf.de/AWMF/l//002-001.htm

5. Busse FP, Fiedler GM, Leichtle A, Hentschel H, Stumvoll M: Lead poisoning due to adulterated Marijuana in Leipzig. Dtsch Arztebl Int 2008; 105: 757-62.

\section{Dr. med. Helmut Hentschel}

Gemeinsames Giftinformationszentrums (GGIZ) der Länder Mecklenburg-Vorpommern, Sachsen, Sachsen-Anhalt und Thüringen, c/o HELIOS Klinikum Erfurt Nordhäuser Str. 74

99089 Erfurt, Germany

leiter@ggiz-erfurt.de

\section{Conflict of interest statement}

The authors of all letters and of the reply declare that no conflict of interest exists according to the guidelines of the International Committee of Medical Journal Editors. 